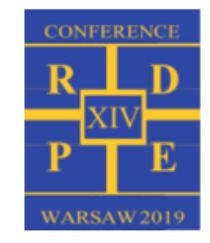

\title{
Experimental and numerical analysis of the biomass innovative solar pyrolysis process
}

\author{
Sebastian W erle ${ }^{1, *}$, Szymon Sobek ${ }^{1}$, Zuzanna Kaczor ${ }^{1}$, Eukasz Ziółkowski ${ }^{1}$, Zbigniew Buliński ${ }^{1}$ and Mariusz Dudziak ${ }^{2}$ \\ ${ }^{1}$ Silesian University of Technology, Institute of Thermal Technology, 22 Konarskiego St, 44-100 Gliwice, Sebastian.werle@polsı.pl, \\ Poland \\ 2 Silesian U niversity of Technology, Institute of W ater and W astewater Engineering, 18 K onarskiego St, 44-100 Gliwice, Poland
}

\begin{abstract}
Paper present the experimental and numerical analysis of biomass photopyrolysis process. The experimental tests is performed on the solar pyrolysis installation, designed in Institute of Thermal Technology, Gliwice. It consist of the copper reactor powered by artificial light simulating sun. The paper shows the result of the solar pyrolysis of wood. The yield of the main fraction as a function of the process temperature is presented. Additionally the gas composition is determined. The numerical model is prepared in the Ansys Fluent 18.2 software, which allow at the same time for capturing geometry of the real system and easy change of input data. The results indicate that both the product yields (liquid, solid and gaseous) and gas components shares are strongly influenced by pyrolysis parameters and feedstock composition.
\end{abstract}

\section{Introduction}

The European Environment Agency (EEA) has estimated that around $235 \mathrm{M}$ toe/year of biomass could be made available in the European U nion (EU) by 2020 without harming the environment [1]. A griculture (95 $\mathrm{M}$ toe), waste (100 $\mathrm{M}$ toe) and wood industry (30 $\mathrm{M}$ toe) are the key suppliers [2]. Due to this fact, in EU countries, biomass is currently one of the main renewable energy sources used to heat and electricity production and for transportation purposes [3]. Moreover, its use is rapidly increasing. Nevertheless, there are a number of restrictions related to the production of biomass, in particular legal solutions concerning the environmental protection and the principles of biodiversity crops. Additionally, the low energy density biomass is distributed in a wide range of remote areas. Therefore, for energy purposes locally available waste products from agriculture, agricultural food industry, spatial and other biodegradable waste, like the sludge should be used [4]. The annual biomass energy potential in Poland is equal to [5]:

- M ore than 20 million $\mathrm{Mg}$ waste straw,

- Approx. 4 million M g of waste wood,

- A pprox. 6 million M g of sewage sludge.

Thermal methods of the waste biomass utilization are gaining importance for many years. The main reason for this fact are the EU requirements because the aim of the European Commission (EC) is to increase the share of the renewable energy sources in overall energy consumption to $32 \%$ by $2030[6,7]$.

The thermal processes include combustion, cocombustion, gasification and pyrolysis [8]. The most common is direct combustion of biomass material. The biggest problems with biomass-fired plants are in handling and pre-processing the fuel. This is the case with both small grate-fired plants and large pulverized coal power plants. Drying the biomass before combustion improves the overall process efficiency, but may not be economically motivated in many cases. Exhaust systems are used to vent combustion byproducts to the environment. Emission controls might include a cyclone or multi-cyclone, a baghouse, or an electrostatic precipitator. The primary function of all of the equipment listed is particulate matter control, and is listed in order of increasing capital cost and effectiveness. Cyclones and multi-cyclones can be used as pre-collectors to remove larger particles upstream of a baghouse (fabric filter) or electrostatic precipitator. In addition, emission controls for unburned hydrocarbons, nitrogen oxides, and sulfur might be required, depending on fuel properties and the Law regulations. Despite the observed ecological, economic and social benefits, the use of biomass creates many technical problems: (1) a wide range of humidity causing difficulty in combustion stabilization, (2) biomass fuels have ash that is more alkaline in nature, which may exaggerate the fouling problems, (3) low density makes it difficult for transportation and storage, (4) high volatile content causing combustion process to be rapid and difficult to control, (5) the relatively low the lower heating value (6) heterogeneity and diversity of composition, including the content of chlorines lead to process during which hydrogen chloride, dioxins and furans are formed [9]. These problems cause that co-combustion of biomass with fossil fuels (mainly hard coal) gained importance. This process can be advantageous with regard to substitution of fossil fuels, reducing fuel cost and emissions of $\mathrm{NO}_{x}$ and $\mathrm{CO}_{2}$ minimizing waste and reduce soil and water pollution and increasing boiler efficiency. 
However, attention must be taken to increase deposit formation in the boiler and limitations in ash use due to compositions in biomass, especially alkali metals, which may disable the use of ash in building materials. Due to undesired changes of ash compositions, the share of biomass is usually limited to approximately $20 \%$ of the fuel input [10]. Additionally, there are other barriers of co-combustion biomass with coal. These barriers include: (1) biomass procurement practices to obtain low-cost fuels in a long term reliable manner; the impact of co-combustion on ash composition and ability to sell fly ash; (2) the trade-off between the impact of biomass on emissions and fuel cost [11]. In case of the Polish market the new Act of the renewable energy sources should be also emphasized [12]. Based on this document, co-financial assistance of the co-combustion installation will be limited.

All presented facts cause that new pioneer and innovative thermal solutions for biomass conversion are needed. A n example of such technology is pyrolysis.

Biomass pyrolysis is defined as a thermal degradation of the biopolymers present in the organic matter under an inert oxygen-free atmosphere [13]. Three products are always produced (solid, liquid and gaseous), but the proportions can be varied over a wide range by adjustment of the process parameters [14]. Pyrolysis is a process carried out at a lower temperature in comparison to combustion or co-combustion [15]. Thanks to it, the formation of toxic substances is limited and the complex gas cleaning system is not necessary. There are many other important advantages of pyrolysis in comparison to combustion, as follows: (1) Pyrolysis can be performed at relatively small scale and at remote locations which enhance energy density of the biomass resource and reduce transport and handling costs; (2) Due to lower temperature of the process corrosion problem is reduced - the maintenance costs of the installation are lower; (3) Due to the lower temperature of the process, recovery of the selected elements (mainly non-ferrous metals) from solid products is possible; (4) Due to the endothermic nature of the pyrolysis, control of the process is easier in comparison to combustion; (5) Pyrolysis is characterized by high level of the fuel flexibility; (6) The pyrolysis products can be stored and later used for energy purposes [16].

Despite its advantages, pyrolysis has the disadvantage of requiring an external energy input to reach the operating temperature [17]. This external energy input is generally derived from a non-renewable source that has a negative impact on the environment. A possible solution to this problem is to use thermo-solar energy to heat the reactor to achieve conditions appropriate for solar pyrolysis initialization. In such process the concentrated solar radiation supplies high temperature heat for biomass pyrolysis reaction [18]. Then biomass and solar energy can be converted into transportable and dispatchable solar fuel [19]. Solar processes has the potential to produce higher calorific value products with lower $\mathrm{CO}_{2}$ emission compared with conventional process [20, 21]. The biomass energy is upgraded through solar energy providing pyrolysis reaction enthalpy transferred into products. Solar pyrolysis is an endothermic process of converting a biomass in an inert atmosphere in which the required heat is provided by concentrated solar energy. The direct solar radiation is concentrated and redirected to the pyrolytic reactor and the biomass to reach pyrolytic temperatures.

Paper present experimental and numerical analysis of wood photopyrolysis process. The yield of the main fraction as a function of the process temperature is presented. Additionally the gas composition is determined. The numerical model is prepared in the Ansys Fluent 18.2 software, which allow at the same time for capturing geometry of the real system and easy change of input data. The results indicate that both the product yields (liquid, solid and gaseous) and gas components shares are strongly influenced by pyrolysis parameters and feedstock composition.

\section{Experiment}

\subsection{Fuel properties}

Table 1 present properties of wood which was used as a feedstock in the solar pyrolysis experiment.

Table 1. Wood analysed properties.

\begin{tabular}{|c|c|c|c|}
\hline Property & Status & Unit & Value \\
\hline M oisture, total & ar & $\%$ mass & 9.00 \\
\hline Ash & dry & $\%$ mass & 0.75 \\
\hline Volatiles & dry & $\%$ mass & 83.3 \\
\hline Higher heating value & ar & $\mathrm{kJ} / \mathrm{kg}$ & 18,760 \\
\hline L ower heating value & ar & $\mathrm{kJ} / \mathrm{kg}$ & 16,870 \\
\hline Carbon & dry & $\%$ vol & 49.61 \\
\hline Hydrogen & dry & $\%$ vol & 5.94 \\
\hline Nitrogen & dry & $\%$ vol & 0.06 \\
\hline Sulphur & dry & $\%$ vol & 0.02 \\
\hline Oxygen & dry & $\% \mathrm{vol}$ & 44.36 \\
\hline Lignin & ar & $\%$ mass & 27.90 \\
\hline Cellulose & ar & $\%$ mass & 54.80 \\
\hline Hemicellulose & ar & $\%$ mass & 11.80 \\
\hline
\end{tabular}

Ultimate and proximate analysis has been determined using plasma spectrometer Thermo iCAP 6500 Duo ICP according to Polish norms: PN-G-04528-02:1977, PNEN 196-2:2013-11, PN-EN 15936:2013-02 and PN-EN 15936:2013-02. Chemical analysis has been carried out using extraction system Ankom A200 and FOSS Fibertec 2010 and 2011 according to application note FOSS 3434 - AOAC 2002:04/ISO 16472:2005

\subsection{Experimental stand}

Figure 1 presents the scheme and the photo of the main elements of the solar installation and Figure 2 shows the view of the xenon arc lamp. 

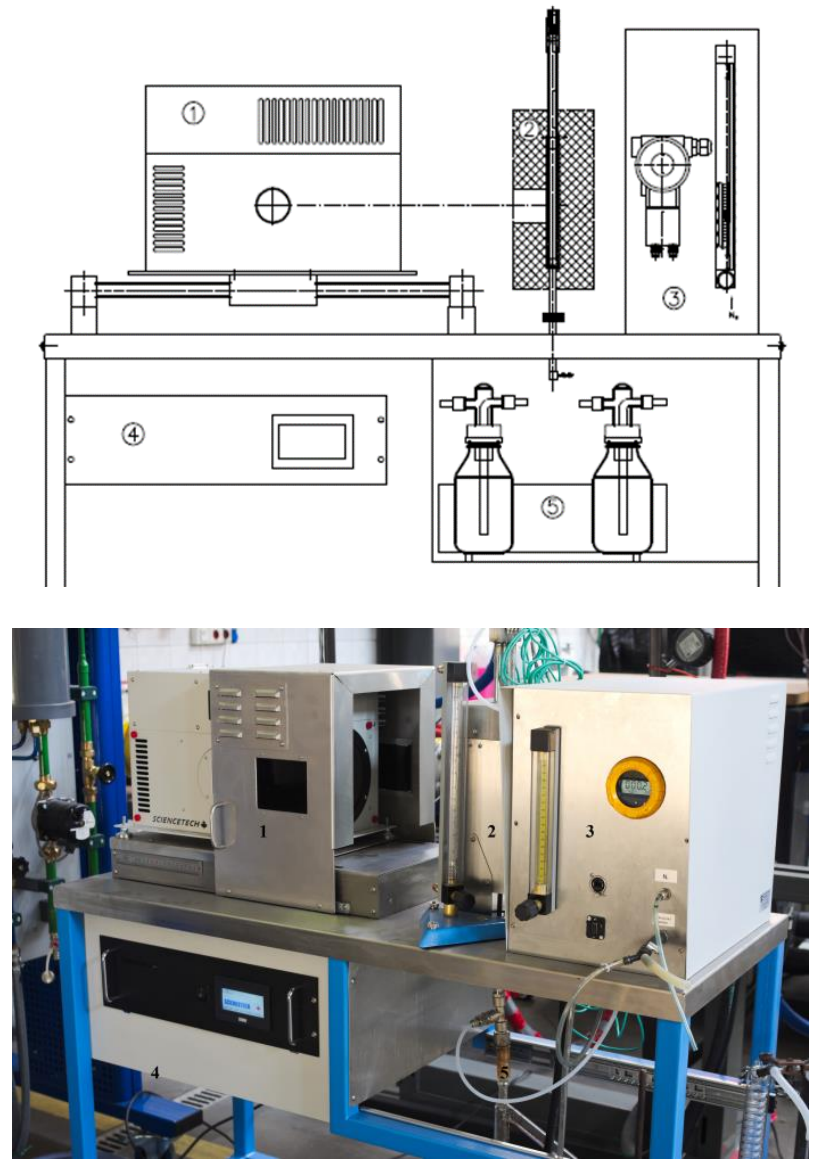

Fig. 1. Experimental setup scheme (upper) and actual photo (lower) of the research stand: 1, xenon arc lamp, 2, insulated reactor, 3, PLC and measurements devices container, 4, lamp power supply, 5, bio-oil condenser.

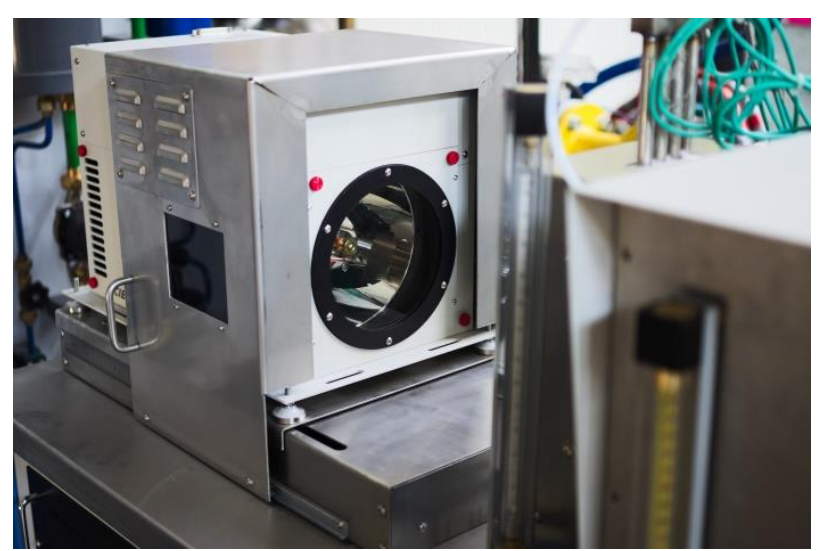

Fig. 2. X enon arc lamp view.

The heart of the laboratory station was artificial sun, the high-power xenon arc lamp. The $1.6 \mathrm{~kW}$ Sciencetech $\odot$ lamp produces stable heat flux in a form of concentrated radiation, with spectral characteristics close to the natural sunlight. Lamp radiation is directed onto reactor surface, containing biomass samples. Reactor is a copper block with four ducted channels, with $169 \mathrm{~mm}$ of total length. $V$ olatiles released during pyrolysis are moved out from reaction zone with flow of inert gas (nitrogen with $1.5 \mathrm{l} / \mathrm{min}$ flow rate) and directed to liquid fraction (biooil) condenser. Bio-oil condenser consists of a set of water- cooled laboratory condensers with assigned Dreshl scrubbers in order to trap condensed bio-oil and pass non-condensable gases to $\mathrm{ABB} C$ gas analyser through Bronkhorst ${ }^{\circledR}$ El-Flow Prestige mass-flow meter.

\subsection{Experimental procedure}

Table 2. The experimental procedure.

\begin{tabular}{|l|l|l|l|}
\hline Fuel form & $\begin{array}{l}\text { Output } \\
\text { power* of } \\
\text { the lamp, } \\
\%\end{array}$ & $\begin{array}{l}\text { Inert** gas } \\
\text { flow, I/min }\end{array}$ & $\begin{array}{l}\text { M easured } \\
\text { parameters }\end{array}$ \\
\hline Wood pellets & 80.0 & 1.5 & $\begin{array}{l}\text { Sample } \\
\text { temperature } \\
\text { Dxh=6x20mm }\end{array}$ \\
85.5 & 90.0 & $\begin{array}{l}\text { Product yield } \\
\text { Gas } \\
\text { composition } \\
\text { shares }\end{array}$ \\
\hline
\end{tabular}

D- outer dimeter

$h$-height

*-maximum power is equal to $1.6 \mathrm{~kW}$

**-nitrogen was used

Table 2 presents the experimental procedure. The total mass of wood feed was 25 grams distributed in four reactor channels in linear form wrapped in copper net. The pyrolysis process was realized in a wide range of temperatures, from approximately 500 to $800{ }^{\circ} \mathrm{C}$. Six K type thermocouples with the outer diameter $0.5 \mathrm{~mm}$ were located in precisely drilled holes in 3 pellets from 2 channels. Control of the process temperature was executed by the variable output power $(80-90 \%)$ of the lamp controlled by the power supply of the lamp. After being loaded with wood pellets, the reactor was exposed to xenon lamp radiation for $90 \mathrm{~min}$ duration time. $M$ easurements were carried out for 3 pre-selected lamp power values $80,85.5$ and $90 \%$. During pyrolysis, the temperature and pyrolysis gas composition were recorded using WAGOC PFC 100 programmable logic controller $(P L C)$. After each test products were separated. The volatiles continuously flew out from the reaction zone with the flow of nitrogen, while bio-oil condensed in the water-cooled condenser, passing dry pyrogas to gas analyser. Solid residue remained in the reactor was removed from the reactor and weighted. Liquid phase was collected from scrubbers and extracted with acetone, then weighted.

\subsection{Experimental results}

Figure 3 presents final results of the study, listing impact of lamp power on following product yields with dry gas composition. Observed trends in product formation are typical for slow pyrolysis, the higher the final temperature and heating rate, the higher the bio-oil yields with lowering amount of dry gas and char. Char yield is strongly correlated to lignin content of the biomass samples (Table 1), bio-oil to cellulose content, and dry-gas to hemicellulose. L ower yield of bio-oil than hemicellulose content can be explained by cracking of tar components to lighter molecules increasing dry gas yield. 
Dry gas quality is typical for slow pyrolysis. Low temperatures favor formation of $\mathrm{CO}_{2}$ and $\mathrm{CO}$, with lower content of $\mathrm{CH}_{4}$ and $\mathrm{H}_{2}$. Finally, the Figure 4 presents indication of gas analyser related to sample temperature for experiment with $80.0 \%$ of lamp power. Peaks of CO and $\mathrm{CO}_{2}$ at around $320^{\circ} \mathrm{C}$ correspond to decomposition of cellulose, while later $\mathrm{CH}_{4}$ and $\mathrm{H}_{2}$ release can be assigned to slow char formation reactions, with wide peaks at $380{ }^{\circ} \mathrm{C}$ and $560{ }^{\circ} \mathrm{C}$ respectively.

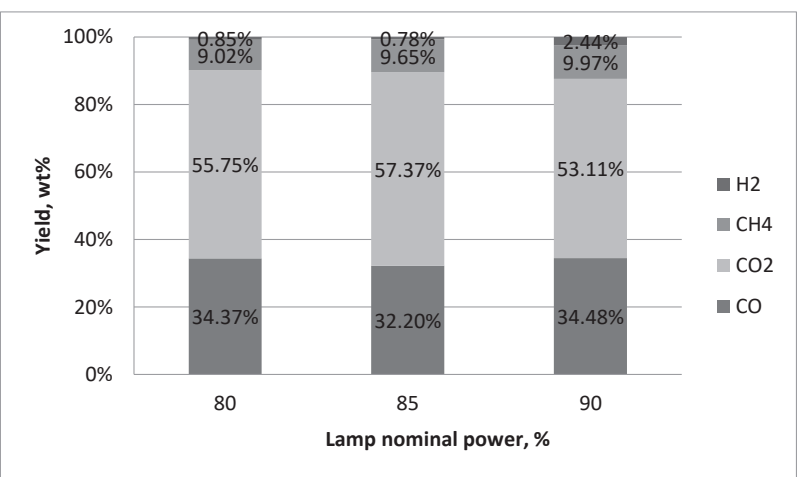

Fig. 3. Effect on lamp power on product yield and pyrogas composition.

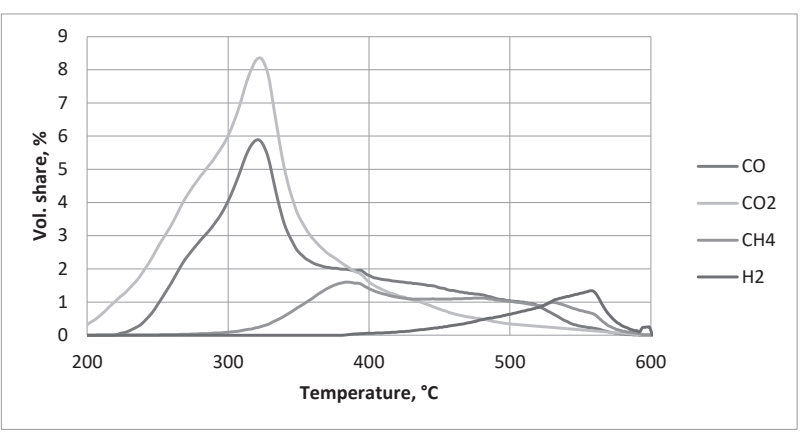

Fig. 4. Gas analyser indications as a function of sample temperature during experiment with $80 \%$ of lamp power.

\section{Numerical investigation}

The main aim of the realization this part of the investigation was definition how to model solar pyrolysis process and what phenomenon must be included in such analysis. The most important el ement of the experimental system is the pyrolytic reactor (Fig. 5), in which four pellet packages are placed in a fixed position which is additionally secured with a copper gauze. The gauze holds the pellets and at the same time allows for free flow of gaseous pyrolysis products out of the reacting bed and for nitrogen flow to provide an inert atmosphere for the process.

The reactor is made of copper. Its outer surface is insulated, except the spot in the middle of its upper surface, where the focused xenon lamp rays fall. This light incidence spot will ultimately be covered with a substance of a high, known absorption capacity.

Nitrogen supplied to the rector will be split to feed all 4 reactor channels. At the outlet of the channels, nitrogen with a mixture of gaseous products (tar and gas) will get through again in a common collector and flow further to the cooling zone, to separate the tar off the gas, which then goes to the analyser.

Such a concept causes that the composition analysis of the process products will average the results for 4 packages of pellets.

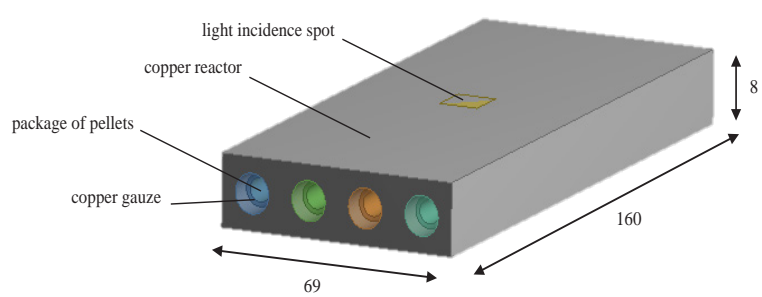

Fig. 5. Pyrolytic reactor scheme for CFD investigation key elements and dimensions (in $\mathrm{mm}$ ).

Based on the the literature review [22 - 26] it can be concluded that the model being prepared within this work can definitely be included into the group of large particles pyrolysis models, where heat and mass transport through the reacting bed requires special attention and obligatory including the changes of physical properties. M oreover, due to the fact that many pellets are simultaneously subjected to pyrolysis, being placed at different distance from the heat source, thus in different thermal conditions, it will be necessary to accurately reflect the geometry of all elements of the reactor, to appropriate capture thermal conditions. The model have to include chemical reactions, heat transfer, physical properties change and moisture evaporation, shrinkage.

\section{Conclusions}

The paper present both theoretical (introduction to CFD modelling) and practise (experiment) aspects of the solar pyrolysis process.

Solar pyrolysis of waste wood can be promising way to utilize waste biomass from wood industry, allowing to produce high-quality, solar enriched, bio-oil and biochar.

Changing the heat transfer conditions is a key element in the mathematical description of the process, especially if the scale of the system is as large as in the presented case.

Evaporation of moisture and deposit shrinkage are essential elements of the pyrolysis process and certainly at further stages of the model development would be a valuable complement to it.

W ithin the experimental part of the paper, solar pyrolysis of waste wood study results has been presented. Experiments have been conducted on solar pyrolysis reactor own-designed by authors. I mpact of investigated biomass chemical composition on actual products distribution and dry gas composition have been presented and discussed. It was confirmed that during wood solar pyrolysis chemical components cellulose, hemicellulose and lignin favours decomposition course leading towards dry gas, bio-oil and bio-char formation respectively. Product shares and dry pyrolysis gas 
quality followed results published in the literature with well-known trends of increasing bio-oil yield with increase of final temperature and average heating rate. $X$ enon-arc lamp provided stable radiant flux and plenty of power. Precise temperature monitor within pellet bed gave insight into samples behaviour during pyrolysis process.

\section{ACKNOWLEDGMENT}

This paper has been prepared within the frame of the project "Study on the solar pyrolysis process of the Waste biomass", financed by the N ational Science Centre, Poland (registration number 2016/23/B/ST 8/02101).

\section{References}

1. European Environment Agency, How much bioenergy can Europe produce without harming the environment, 2006, p. 6.

2. Eurostat main tables, IEA, WEO 2011, Annexes, p. 26.

3. Marculescu C., Comparative A nalysis on Waste to Energy Conversion Chains Using Thermal-Chemical Processes, Energy Procedia, 18, pp. 604-611, (2012).

4. Magdziarz A., Wilk M., Thermal characteristics of the combustion process of biomass and sewage sludge, Journal of Thermal Analysis and Calorimetry, 14, pp. 519-529, (2013).

5. Werle S. Wilk R.K., A review of methods for the thermal utilization of sewage sludge: the Polish perspective, Renewable Energy, 35, pp. 1914-1919 (2010).

6. Refuse derived fuel, current practice and perspectives - Final Report, European Commission - Directorate General Environment 2003.

7. Report from the Commission to the European Parliament and the Council on the implementation of the EU Strategy on adaptation to climate change, COM (2018)0738, 12 November 2018.

8. Communication from the Commission of 7 December 2005 - B iomass A ction Plan

9. W erle S., Impact of feedstock properties and operating conditions on sewage sludge gasification in a fixed bed gasifier, Waste Management and Research, 32, pp. 954-960, (2014)

10. W erther J. Saenger M. Hartge E.-U, Ogada $T$, Siagi $Z$, Combustion of agricultural residues, Progress in Energy and Combustion Science, 26, pp. 1-27, (2000).

11. Khan A.A., de Jong W., Jansens P.J., Spliethoff $H_{\text {., }}$ Biomass combustion in fluidized bed boilers: potential problems and remedies, Fuel Processing Technology, 90, pp. 21-50, (2009).

12. Smoot L.D., International research centers' activities in coal combustion. Progress in
Energy and Combustion Science, 24, pp. 409-501, (1998).

13. Act of the renewable energy sources (Dz. U. 2015 poz. 478), Poland, 20 February 2015r.

14. Rutkowski P., Kubacki A., Influence of polystyrene addition to cellulose on chemical structure and properties of bio-oil obtained during pyrolysis, Energy Conversion and Management, 47, pp. 716-731, (2006).

15. Y aman S., Pyrolysis of biomass to produce fuels and chemical feedstock, Energy Conversion and Management, 45, pp. 651671, (2004).

16. Basu P., Biomass gasification and pyrolysis. Practical design and theory, Elsevier, 2010.

17. Zeng K., Minh D.P., Gauthier D., WeissHortala E., Nzihou A., Flamant G., The effect of temperature and heating rate on char properties obtained from solar pyrolysis of beech wood, Bioresource Technology, 182, pp. 114-119, (2015).

18. M orales S., M iranda R., Bustos D. Cazares T., Tran H., Solar biomass pyrolysis for the production of bio-fuels and chemical commodities, Journal of Analytical and Applied Pyrolysis, 109, pp. 65-78, (2014).

19. Piatkowski N., W ieckert C., W eimer AW., Steinfeld A., Solar-driven gasification of carbonaceous feedstock - a review, Energy and Environmental Science, 4, pp. 73-82, (2011).

20. Chueh W.C., Falter C., A bbott M., Scipio D., Furler P., Haile S.M., Steinfeld A., Highflux solar-driven thermochemical dissociation of $\mathrm{CO}_{2}$ and $\mathrm{H}_{2} \mathrm{O}$ using nonstoichiometric ceria, Science, 330, pp. 1797-801, (2010).

21. Nzihou A., Flamant G., Stanmore B., Synthetic fuels from biomass using concentrated solar energy - a review, Energy, 42, pp. 121-31, (2011).

22. Grønli M.G., M elaaen M.C., M athematical model for wood pyrolysis - Comparison of experimental measurements with model predictions, Energy \& Fuels, vol. 14, no. 4, pp. 791-800, (2000).

23. Blondeau J., J eanmart $\mathrm{H}$., Biomass pyrolysis at high temperatures: Prediction of gaseous species yields from an anisotropic particle, Biomass and Bioenergy, vol. 41, pp. 107121, (2012).

24. X ue Q., Dalluge D., Heindel T.J., Fox R.O., Brown R.C., Experimental validation and CFD modeling study of biomass fast pyrolysis in fluidized-bed reactors, Fuel, vol. 97, pp. 757-769, (2012).

25. Tolvanen H., Kokko L., Raiko R., Fast pyrolysis of coal, peat, and torrefied wood: Mass loss study with a drop-tube reactor , particle geometry analysis, and kinetics modeling, Fuel, vol. 111, pp. 148-156, (2013). 
26. Y u X., Hassan M., Ocone R., Y. M akkawi $Y_{\text {., }}$ A CFD study of biomass pyrolysis in a downer reactor equipped with a novel gassolid separator-ll thermochemical performance and products Fuel Processing Technoogy., vol. 133, pp. 51-63, (2015). 